\title{
Wax Inhibition by Comb-Like Polymers: Support of the Incorporation-Perturbation Mechanism from Molecular Dynamics Simulations
}

\author{
Yun Hee Jang, ${ }^{\S, \dagger}$ Mario Blanco, ${ }^{\S}$ Jefferson Creek, ${ }^{\top}$ Yongchun Tang, ${ }^{\top}$ and William A. Goddard, III*, \\ ${ }^{\S}$ Materials and Process Simulation Center (MC139-74), California Institute of Technology, Pasadena, California 91125. "Chevron Energy \\ Technology Company, 1600 Smith St., Houston TX 77002. \\ *To whom correspondence should be sent (Phone 626-395-2731, Fax 626-585-0918, E-mail wag@wag.caltech.edu).
}

\section{Supporting Information}

\section{S1. Force field for $n$-alkanes (oil, wax, tail of inhibitor)}

The methylene $\left(\mathrm{CH}_{2}\right)$ and methyl $\left(\mathrm{CH}_{3}\right)$ groups in $n$-alkanes (oil solvent, wax, and long alkyl tails of inhibitors) were treated as united atoms, that is, each $\mathrm{CH}_{2}$ or $\mathrm{CH}_{3}$ unit was treated as a single neutral pseudoatom. The force field (FF) for these united atoms (Table S1) was mostly taken from the SKS (Siepmann-Karanorni-Smit) FF. ${ }^{1-3}$ The bond-stretching force constant, which is not in the original SKS FF, was taken from the AMBER FF. ${ }^{4,5}$ The torsion potential of the SKS FF had been taken from the OPLS (Optimized Potentials for Liquid Simulation) FF. ${ }^{6}$ The nonbonded interactions between 1-2, 1-3, and 1-4 neighbors were excluded, and other nonbonded interactions were truncated by a cubic spline cutoff function defined to be 1 for $r<13.8 \AA$, 0 for $r>14.3 \AA$, and decrease smoothly in between. The offdiagonal vdW parameters between $\mathrm{CH}_{2}$ and $\mathrm{CH}_{3}$ are given by the geometric means of diagonal ones:

$$
R_{0}^{\mathrm{AB}}=\sqrt{R_{0}^{\mathrm{A}} R_{0}^{\mathrm{B}}} \text { and } D_{0}^{\mathrm{AB}}=\sqrt{D_{0}^{\mathrm{A}} D_{0}^{\mathrm{B}}} .
$$

Table S1. Force field used for $n$-alkanes.

\begin{tabular}{|c|c|c|c|c|c|c|c|}
\hline$E^{v d W}(R)=D_{\mathrm{c}}$ & $D_{0}\left\{\left(\frac{R_{0}}{R}\right)^{12}-2\left(\frac{R_{0}}{R}\right)^{6}\right.$ & $E^{\text {bond }}(R)=$ & $=\frac{1}{2} K_{R}\left(R-R_{0}\right)^{2}$ & $E^{\text {angle }}(\theta)=\frac{1}{2}$ & $\frac{1}{2} K_{\theta}\left(\theta-\theta_{0}\right)^{2}$ & $E^{\text {torsion }}(\phi)=\sum_{n} \frac{1}{2} V_{n}$ & {$\left[1-d_{n} \cos (n \phi)\right]$} \\
\hline \multirow[t]{2}{*}{$E^{\mathrm{vdW}}$} & $\mathrm{CH}_{2}$ & $R_{0}{ }^{a}$ & 4.4113 & $D_{0}{ }^{\mathrm{b}}$ & 0.09339 & & \\
\hline & $\mathrm{CH}_{3}$ & $R_{0}^{\mathrm{a}}$ & 4.4113 & $D_{0}{ }^{\mathrm{b}}$ & 0.2265 & & \\
\hline \multirow[t]{2}{*}{$E^{\text {bond }}$} & $\mathrm{CH}_{2}-\mathrm{CH}_{2}$ & $R_{0}{ }^{\mathrm{a}}$ & 1.54 & $K_{\mathrm{b}}{ }^{\mathrm{c}}$ & 520 & & \\
\hline & $\mathrm{CH}_{2}-\mathrm{CH}_{3}$ & $R_{0}{ }^{\mathrm{a}}$ & 1.54 & $K_{\mathrm{b}}{ }^{\mathrm{c}}$ & 520 & & \\
\hline \multirow[t]{2}{*}{$E^{\text {angle }}$} & $\mathrm{CH}_{2}-\mathrm{CH}_{2}-\mathrm{CH}_{2}$ & $\theta_{0}^{\mathrm{d}}$ & 114 & $K_{\theta}{ }^{\mathrm{e}}$ & 124.19 & & \\
\hline & $\mathrm{CH}_{2}-\mathrm{CH}_{2}-\mathrm{CH}_{3}$ & $\theta_{0}^{\mathrm{d}}$ & 114 & $K_{\theta}^{\mathrm{e}}$ & 124.19 & & \\
\hline \multirow[t]{2}{*}{$E^{\text {torsion }}$} & $\mathrm{CH}_{2}-\mathrm{CH}_{2}-\mathrm{CH}_{2}-\mathrm{CH}_{2}$ & $V_{1}^{\mathrm{b}}\left(d_{1}\right)$ & $1.4109(-1)$ & $V_{2}^{\mathrm{b}}\left(d_{2}\right)$ & $-0.271(1)$ & $V_{3}^{\mathrm{b}}\left(d_{3}\right)$ & $2.787(-1)$ \\
\hline & $\mathrm{CH}_{2}-\mathrm{CH}_{2}-\mathrm{CH}_{2}-\mathrm{CH}_{3}$ & $V_{1}^{\mathrm{b}}\left(d_{1}\right)$ & $1.4109(-1)$ & $V_{2}^{\mathrm{b}}\left(d_{2}\right)$ & $-0.271(1)$ & $V_{3}^{\mathrm{b}}\left(d_{3}\right)$ & $2.787(-1)$ \\
\hline
\end{tabular}

${ }^{\mathrm{a}} \mathrm{In} \AA$. This $R_{0}$ has been converted from the original literature value $\sigma$ by the relation $R_{0}=\sqrt[6]{2} \sigma$, since in the original literature $E^{\mathrm{vdW}}$ was defined as $E^{v d W}(R)=4 \varepsilon\left\{\left(\frac{\sigma}{R}\right)^{12}-\left(\frac{\sigma}{R}\right)^{6}\right\}$.

${ }^{\mathrm{b}}$ In $\mathrm{kcal} / \mathrm{mol}$. This $D_{0}(\mathrm{kcal} / \mathrm{mol})$ has been converted from the original literature value $\varepsilon\left(=D_{0} / k\right.$ where $k$ is the Boltzmann constant; K) by the relation by $\varepsilon \times$ $k$. ${ }^{\mathrm{C}}$ In $\mathrm{kcal} / \mathrm{mol} / \AA^{2}$. ${ }^{\mathrm{d}}$ In degrees. ${ }^{\mathrm{e}} \mathrm{In} \mathrm{kcal} / \mathrm{mol} / \mathrm{rad}^{2}$.

\section{S2. Force field for the backbone of inhibitor}

The FF for the acrylate backbone (Table S2 and Figures S1-S2) was mostly taken from the OPLS FF developed for liquid methyl acetate $^{7,8}$ except several following modifications.

Atomic charges of the acrylate backbone (-CHCOO-) were refined by $a b$ initio quantum mechanics (QM) calculation on a model compound representing the acrylate group, $\left(\mathrm{CH}_{3}\right)_{2} \mathrm{CHCOOCH}_{2} \mathrm{CH}_{3}$ (Figure S1a). The calculation was done at $\mathrm{HF} / 6-31 \mathrm{G} * *$ level using Jaguar v3.5. ${ }^{9}$ The atomic charges were fitted to reproduce the electrostatic potential derived from the wavefunction by the CHELP method (ESP-fitted charges). ${ }^{11-13}$ Because the charges of the methyl groups, which will be replaced by neutral united atoms in simulations, were close to zero within 0.1 |e| (Figure S1a), they were constrained to zero in a new ESP fitting to determine the charges of the rest of the molecule (Figure S1b). The resulted atomic charges were reasonably similar to those used in the OPLS FF (Figure S1c).

The force constants for bond stretching, angle bending, and inversion, which are not in the original OPLS FF, were taken from the AMBER FF (Figures S2b-c). 
The torsion FF was refined to reproduce the torsion potential curves obtained from HF/6-31G** QM calculations on small model compounds. The QM torsion potential was calculated by optimizing geometrical parameters at a series of fixed values of a torsion angle of interest.

A model compound $\left(\mathrm{CH}_{3} \mathrm{CH}_{2}\right)_{2} \mathrm{CHCOOCH}_{3}$ (Figures S3a-b) was employed to obtain the potential along the $\mathrm{CH}$ - $\mathrm{CH}-\mathrm{C}=\mathrm{O}$ torsion angle. The conformation with $\mathrm{H}-\mathrm{C}-\mathrm{C}=\mathrm{O}$ at $180^{\circ}$ (Figure S3b) is $0.3 \mathrm{kcal} / \mathrm{mol}$ lower than the conformation with $\mathrm{H}-\mathrm{C}-\mathrm{C}=\mathrm{O}$ at $0^{\circ}$ (Figure S3a), and these two minima are separated by a barrier of $4.2 \mathrm{kcal} / \mathrm{mol}$. This $\mathrm{QM}$ potential for the $\mathrm{CH}_{2}-\mathrm{CH}-\mathrm{C}=\mathrm{O}$ torsion angle was reproduced very well (Figure 6a) by choosing appropriate torsion parameters.

A model compound $\left(\mathrm{CH}_{3}\right)_{2} \mathrm{CHCOOCH}_{2} \mathrm{CH}_{3}$ (Figure S3c) was employed for the potential along the $\mathrm{CH}-\mathrm{C}-\mathrm{O}-\mathrm{CH}_{2}$ torsion angle. Since both conformations with $\mathrm{H}-\mathrm{C}-\mathrm{C}=\mathrm{O}$ at $0^{\circ}$ and at $180^{\circ}$ are shown above to have significant populations and not to convert to each other easily with a barrier of $4.2 \mathrm{kcal} / \mathrm{mol}$, the $\mathrm{CH}-\mathrm{C}-\mathrm{O}-\mathrm{CH}_{2}$ torsion potential was calculated for both cases: Figures S3c and S4c show the case where $\mathrm{H}-\mathrm{C}-\mathrm{C}=\mathrm{O}$ is at $0^{\circ}$ and Figures S3d and S4d show the case where $\mathrm{H}-\mathrm{C}-\mathrm{C}=\mathrm{O}$ is at $180^{\circ}$. In any case, the trans conformation where $\mathrm{C}$ $\mathrm{C}-\mathrm{O}-\mathrm{C}$ is at $180^{\circ}$ (Figure S4c) is more stable by $10-16 \mathrm{kcal} / \mathrm{mol}$ than the cis conformation where C-C-O-C is at $0^{\circ}$ (Figures $\mathrm{S} 4 \mathrm{c}-\mathrm{d}$ ), obviously because of the repulsion between the $-\mathrm{CH}_{2}-\left(\right.$ or $\left.-\mathrm{CH}_{3}\right)$ groups located close to each other in the cis conformation. This $\mathrm{CH}-\mathrm{C}-\mathrm{O}-$ $\mathrm{CH}_{2}$ torsion potential was reproduced reasonably well by choosing appropriate torsion parameters (Figures S4c-d and Table S2).

Two model compounds, $\left(\mathrm{CH}_{3}\right)_{2} \mathrm{CHCOOCH}_{2} \mathrm{CH}_{3}$ (Figure S3c) and $\mathrm{CH}_{3} \mathrm{COOCH}_{2} \mathrm{CH}_{2} \mathrm{CH}_{3}$ (Figures S3d-e) were used to calculate the torsion potential along C-O- $\mathrm{CH}_{2}-\mathrm{CH}_{2}$ (or $-\mathrm{CH}_{3}$ ). These two compounds gave essentially the same C-O- $\mathrm{CH}_{2}-\mathrm{CH}_{2}$ torsion potential quantum mechanically (Figure S4b). This torsion is relatively free (with a barrier less than $1.2 \mathrm{kcal} / \mathrm{mol}$ ) unless the $-\mathrm{CH}_{2}-$ or $-\mathrm{CH}_{3}$ group approaches the carbonyl oxygen $(=\mathrm{O})$ too close in the cis conformation with $\mathrm{C}-\mathrm{O}-\mathrm{CH}_{2}-\mathrm{CH}_{2}$ at $0^{\circ}$, where the energy is $8 \mathrm{kcal} / \mathrm{mol}$ higher than the trans conformation with $\mathrm{C}-\mathrm{O}-\mathrm{CH}_{2}-\mathrm{CH}_{2}$ at $180^{\circ}$. The FF calculation with appropriately chosen parameters reproduces the overall shape of this QM torsion potential, but gives too high energy for the cis conformation ( $11 \mathrm{kcal} / \mathrm{mol}$ higher than the trans conformation; Figure S4b). This is thought to be because the united atom model in the FF calculation exaggerates the repulsion between the $\mathrm{CH}_{2}$ pseudoatom and the carbonyl oxygen in the cis configuration; there would be no attractive interaction between $\mathrm{O}$ and $\mathrm{H}$ of $\mathrm{CH}_{2}$ unit in this united atom model. However, the problematic range showing a discrepancy between QM and FF $\left(\mathrm{C}-\mathrm{O}-\mathrm{CH}_{2}-\mathrm{CH}_{2}<40^{\circ}\right)$ is accessible only with a high energy (at least $3 \mathrm{kcal} / \mathrm{mol}$ higher than the trans conformation; Figure S4b), and thus the contribution of this range is expected to be very small.

Table S2. Force field used for the acrylate backbone of the inhibitor.

\begin{tabular}{|c|c|c|c|c|c|c|c|}
\hline \multicolumn{2}{|c|}{$E^{v d W}(R)=D_{0}\left\{\left(\frac{R_{0}}{R}\right)^{12}-2\left(\frac{R_{0}}{R}\right)\right.$} & \multirow{2}{*}{$\begin{array}{l}E^{\text {bond }}(R) \\
R_{0}^{\mathrm{a}}\end{array}$} & \multirow{2}{*}{$\frac{\frac{1}{2} K_{R}\left(R-R_{0}\right)^{2}}{3.3225}$} & \multicolumn{2}{|c|}{$E^{\text {angle }}(\theta)=\frac{1}{2} K_{\theta}\left(\theta-\theta_{0}\right)^{2}}$, & \multicolumn{2}{|c|}{$E^{\text {torsion }}(\phi)=\sum_{n} \frac{1}{2} V_{n}\left[1-d_{n} \cos (n \phi)\right]$} \\
\hline \multirow[t]{5}{*}{$E^{\mathrm{vdW}}$} & $=\mathrm{O}\left(s p^{2}\right)$ & & & $D_{0}{ }^{\mathrm{b}}$ & 0.210 & & \\
\hline & $-\mathrm{O}-\left(s p^{3}\right)$ & $R_{0}{ }^{\mathrm{a}}$ & 3.3674 & $D_{0}{ }^{\mathrm{b}}$ & 0.170 & & \\
\hline & $C\left(s p^{2}\right)$ & $R_{0}^{\mathrm{a}}$ & 4.2092 & $D_{0}{ }^{\mathrm{b}}$ & 0.105 & & \\
\hline & $\mathrm{C}\left(s p^{3}\right)$ & $R_{0}$ & 3.8050 & $D_{0}$ & 0.06921 & & \\
\hline & $\mathrm{H}$ & $R_{0}$ & 2.9267 & $D_{0}$ & 0.0335 & & \\
\hline \multirow[t]{6}{*}{$E^{\text {bond }}$} & $\mathrm{C}\left(s p^{2}\right)=\mathrm{O}$ & $R_{0}{ }^{\mathrm{a}}$ & 1.200 & $K_{\mathrm{b}}{ }^{\mathrm{c}}$ & 1140 & & \\
\hline & $\mathrm{C}\left(s p^{2}\right)-\mathrm{O}$ & $R_{0}{ }^{\mathrm{a}}$ & 1.344 & $K_{\mathrm{b}}{ }^{\mathrm{c}}$ & 900 & & \\
\hline & $\mathrm{O}-\mathrm{CH}_{2} / \mathrm{CH}_{3}$ & $R_{0}{ }^{\mathrm{a}}$ & 1.437 & $K_{\mathrm{b}}{ }^{\mathrm{c}}$ & 640 & & \\
\hline & $\mathrm{C}\left(s p^{2}\right)-\mathrm{C}\left(s p^{3}\right)$ & $R_{0}{ }^{a}$ & 1.520 & $K_{\mathrm{b}}{ }^{\mathrm{c}}$ & 634 & & \\
\hline & $\mathrm{C}\left(s p^{3}\right)-\mathrm{H}$ & $R_{0}$ & 1.09 & $K_{\mathrm{b}}$ & 662 & & \\
\hline & $\mathrm{C}\left(s p^{3}\right)-\mathrm{CH}_{2} / \mathrm{CH}_{3}$ & $R_{0}$ & 1.54 & $K_{\mathrm{b}}$ & 520 & & \\
\hline \multirow[t]{9}{*}{$E^{\text {angle }}$} & $\mathrm{O}=\mathrm{C}\left(s p^{2}\right)-\mathrm{O}$ & $\theta_{0}^{\mathrm{d}}$ & 125 & $K_{\theta}{ }^{\mathrm{e}}$ & 160 & & \\
\hline & $\mathrm{O}=\mathrm{C}\left(s p^{2}\right)-\mathrm{C}\left(s p^{3}\right)$ & $\theta_{0}^{\mathrm{d}}$ & 125 & $K_{\theta}{ }^{\mathrm{e}}$ & 160 & & \\
\hline & $\mathrm{O}-\mathrm{C}\left(s p^{2}\right)-\mathrm{C}\left(s p^{3}\right)$ & $\theta_{0}^{\mathrm{d}}$ & 110 & $K_{\theta}{ }^{\mathrm{e}}$ & 140 & & \\
\hline & $\mathrm{C}\left(s p^{2}\right)-\mathrm{O}-\mathrm{CH}_{2} / \mathrm{CH}_{3}$ & $\theta_{0}^{\mathrm{d}}$ & 115 & $K_{\theta}{ }^{\mathrm{e}}$ & 200 & & \\
\hline & $\mathrm{O}-\mathrm{CH}_{2}-\mathrm{CH}_{2} / \mathrm{CH}_{3}$ & $\theta_{0}^{\mathrm{d}}$ & 109.5 & $K_{\theta}{ }^{\mathrm{e}}$ & 160 & & \\
\hline & $\mathrm{H}-\mathrm{C}\left(s p^{3}\right)-\mathrm{C}\left(s p^{2}\right)$ & $\theta_{0}^{\mathrm{d}}$ & 109.5 & $K_{\theta}^{\mathrm{e}}$ & 70 & & \\
\hline & $\mathrm{H}-\mathrm{C}\left(s p^{3}\right)-\mathrm{CH}_{2}$ & $\theta_{0}^{\mathrm{d}}$ & 109.5 & $K_{\theta}{ }^{\mathrm{e}}$ & 70 & & \\
\hline & $\mathrm{CH}_{2}-\mathrm{C}\left(s p^{3}\right)-\mathrm{CH}_{2}$ & $\theta_{0}^{\mathrm{d}}$ & 114 & $K_{\theta}{ }^{\mathrm{e}}$ & 124.19 & & \\
\hline & $\mathrm{CH}_{2}-\mathrm{C}\left(s p^{3}\right)-\mathrm{C}\left(s p^{2}\right)$ & $\theta_{0}^{\mathrm{d}}$ & 111.1 & $K_{\theta}^{\mathrm{e}}$ & 126 & & \\
\hline \multirow[t]{9}{*}{$E^{\text {torsion }}$} & $\mathrm{C}-\mathrm{CH}_{2}-\mathrm{C}-\mathrm{CH}_{2}$ & $V_{1}^{\mathrm{b}}\left(d_{1}\right)$ & $-0.50(+1)$ & $V_{2}^{\mathrm{b}}\left(d_{2}\right)$ & $1.70(-1)$ & & \\
\hline & & $V_{3}^{\mathrm{b}}\left(d_{3}\right)$ & $-0.44(+1)$ & $V_{4}^{\mathrm{b}}\left(d_{4}\right)$ & $1.75(-1)$ & & \\
\hline & $\mathrm{O}=\mathrm{C}-\mathrm{C}-\mathrm{CH}_{2}$ & $V_{1}^{\mathrm{b}}\left(d_{1}\right)$ & $0.42(+1)$ & $V_{2}^{\mathrm{b}}\left(d_{2}\right)$ & $0.38(+1)$ & $V_{3}^{\mathrm{b}}\left(d_{3}\right)$ & $0.17(+1)$ \\
\hline & $\mathrm{O}-\mathrm{C}-\mathrm{C}-\mathrm{CH}_{2}$ & $V_{1}^{\mathrm{b}}\left(d_{1}\right)$ & $0.42(-1)$ & $V_{2}^{\mathrm{b}}\left(d_{2}\right)$ & $0.38(+1)$ & $V_{3}^{\mathrm{b}}\left(d_{3}\right)$ & $0.17(+1)$ \\
\hline & $\mathrm{C}-\mathrm{C}-\mathrm{O}-\mathrm{CH}_{2} / \mathrm{CH}_{3}$ & $V_{1}^{\mathrm{b}}\left(d_{1}\right)$ & $0.54(+1)$ & $V_{2}^{\mathrm{b}}\left(d_{2}\right)$ & $6.18(+1)$ & & \\
\hline & & $V_{3}^{\mathrm{b}}\left(d_{3}\right)$ & $0.38(-1)$ & $V_{4}^{\mathrm{b}}\left(d_{4}\right)$ & $0.17(-1)$ & & \\
\hline & $\mathrm{O}=\mathrm{C}-\mathrm{O}-\mathrm{CH}_{2} / \mathrm{CH}_{3}$ & $V_{1}^{\mathrm{b}}\left(d_{1}\right)$ & $0.54(-1)$ & $V_{2}^{\mathrm{b}}\left(d_{2}\right)$ & $6.18(+1)$ & & \\
\hline & & $V_{3}^{\mathrm{b}}\left(d_{3}\right)$ & $0.38(+1)$ & $V_{4}^{\mathrm{b}}\left(d_{4}\right)$ & $0.17(-1)$ & & \\
\hline & $\mathrm{C}-\mathrm{O}-\mathrm{CH}_{2}-\mathrm{CH}_{2} / \mathrm{CH}_{3}$ & $V_{1}^{\mathrm{b}}\left(d_{1}\right)$ & $2.14(+1)$ & $V_{2}^{\mathrm{b}}\left(d_{2}\right)$ & $0.79(+1)$ & $V_{3}^{\mathrm{b}}\left(d_{3}\right)$ & $1.29(-1)$ \\
\hline
\end{tabular}

${ }^{\mathrm{a}}$ In $\AA$. This $R_{0}$ has been converted from the original literature value $\sigma$ by the relation $R_{0}=\sqrt[6]{2} \sigma$, since in the original literature $E^{\mathrm{vdW}}$ is defined as $E^{v d W}(R)=4 \varepsilon\left\{\left(\frac{\sigma}{R}\right)^{12}-\left(\frac{\sigma}{R}\right)^{6}\right\}$.

${ }^{\mathrm{b}} \mathrm{In} \mathrm{kcal} / \mathrm{mol}$. This $D_{0}(\mathrm{kcal} / \mathrm{mol})$ has been converted from the original literature value $\varepsilon\left(=D_{0} / k\right.$ where $k$ is the Boltzmann constant; K) by the relation by $\varepsilon \times$ k. ${ }^{\mathrm{C}}$ In $\mathrm{kcal} / \mathrm{mol} / \AA^{2}$. ${ }^{\mathrm{d}}$ In degrees. ${ }^{\mathrm{e}} \mathrm{In} \mathrm{kcal} / \mathrm{mol} / \mathrm{rad}^{2}$. 


$$
\text { (1) }-0.07
$$

(a)

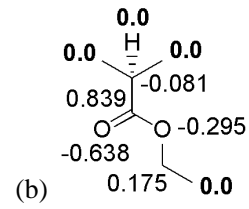

(b)

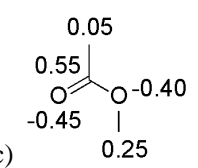

Figure S1. Atomic charges for the acrylate backbone of PAA1. (a) ESP-fitted charges from ab initio QM calculation, (b) ESP-fitted charges with constraints (denoted in bold face) on the methyl groups which will be replaced by neutral united atoms in simulations, and (c) atomic charge parameter used in OPLS FF. Charges in (b) were used in the simulations.

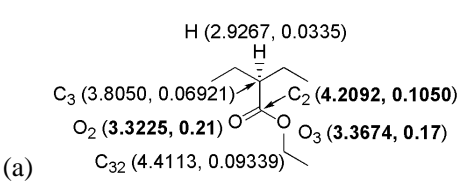

(b)

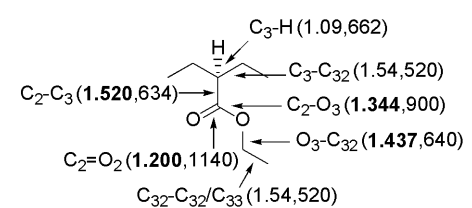

(c)

Figure S2. Force field for the acrylate backbone of the PAA1 inhibitor. Numbers in bold faces are taken from the OPLS FF. $\mathrm{C}_{32}$ and $\mathrm{C}_{33}$ represent united atoms for $\mathrm{CH}_{2}$ and $\mathrm{CH}_{3}$ groups, respectively. (a) vdW FF, $R_{0}(\AA)$ and $D_{0}(\mathrm{kcal} / \mathrm{mol})$; (b) bond stretching $\mathrm{FF}, R_{0}(\AA)$ and $K_{\mathrm{b}}\left(\mathrm{kcal} / \mathrm{mol} / \AA^{2}\right)$; (c) angle bending $\mathrm{FF}, \theta_{0}(\AA)$ and $K_{\theta}\left(\mathrm{kcal} / \mathrm{mol} / \mathrm{rad}^{2}\right)$. Functionals forms are given in Table S1.

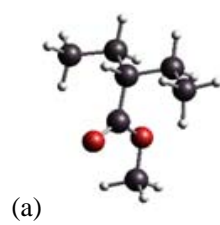

(a)

(b)

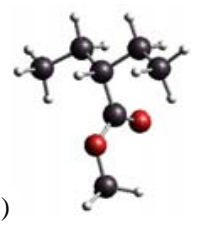

(c)

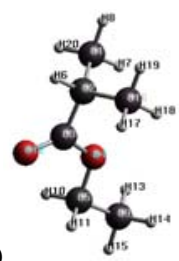

(d)

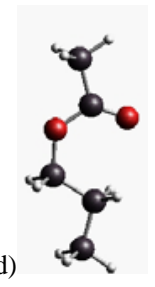

(e)

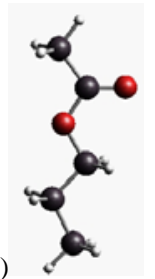

Figure S3. Model compounds used to obtain torsion potentials. (a-b) $\left(\mathrm{CH}_{3} \mathrm{CH}_{2}\right)_{2} \mathrm{CHCOOCH}_{3}$ for torsion $\mathrm{CH}_{2}-\mathrm{CH}-\mathrm{C}=\mathrm{O}\left(\mathrm{a}\right.$ : $0^{\circ}$ and b: $\left.180^{\circ}\right)$ and $(\mathrm{c}-\mathrm{e})$ $\left(\mathrm{CH}_{3}\right)_{2} \mathrm{CHCOOCH}_{2} \mathrm{CH}_{3}$ (c) and $\mathrm{CH}_{3} \mathrm{COOCH}_{2} \mathrm{CH}_{2} \mathrm{CH}_{3}$ (d-e) for torsion C-O- $\mathrm{CH}_{2}-\mathrm{CH}_{2}$ (c: $0^{\circ}$ and d-e: $180^{\circ}$ ). These two different models give essentially the same potential energy curves (dots in Figure S4b).

(a)

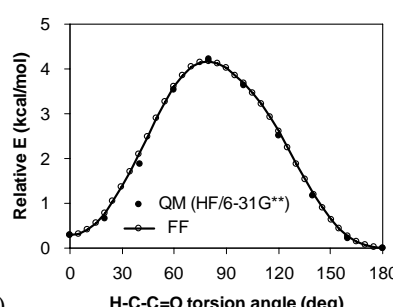

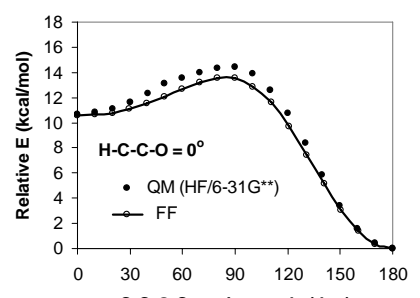

(c)

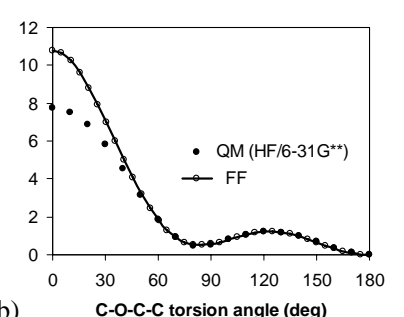

(b)

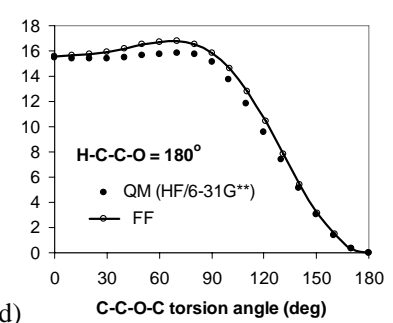

(d)

Figure 6. Torsion potential curves calculated on model compounds using QM (filled circle) and FF (solid line with open circles). (a) Torsion potential along $\mathrm{CH}_{2}-\mathrm{CH}-\mathrm{C}=\mathrm{O}$ of $\left(\mathrm{CH}_{3} \mathrm{CH}_{2}\right)_{2} \mathrm{CHCOOCH}_{3}$ (Figures S3a-b), (b) torsion potential along $\mathrm{C}-\mathrm{O}-\mathrm{CH}_{2}-\mathrm{CH}_{2}$ of $\left(\mathrm{CH}_{3}\right)_{2} \mathrm{CHCOOCH}_{2} \mathrm{CH}_{3}(\mathrm{Figure} \mathrm{S} 3 \mathrm{c})$ and $\mathrm{CH}_{3} \mathrm{COOCH}_{2} \mathrm{CH}_{2} \mathrm{CH}_{3}$ (Figures S3d-e), and (c-d) torsion potential along $\mathrm{CH}-\mathrm{C}-\mathrm{O}-\mathrm{CH}_{2}$ of $\left(\mathrm{CH}_{3}\right)_{2} \mathrm{CHCOOCH}_{2} \mathrm{CH}_{3}$ (Figure S3c) when $\mathrm{H}-\mathrm{C}-\mathrm{C}=\mathrm{O}$ is $0^{\circ}$ (c) or $180^{\circ}(\mathrm{d})$.

\section{References}

(1) Siepmann, J. I.; Karaborni, S.; Smit, B. Nature 1993, 365, 330-332.

(2) Smit, B.; Karaborni, S.; Siepmann, J. I. J. Chem. Phys. 1995, 102, 2126-2140.

(3) Martin, M. G.; Siepmann, J. I. J. Am. Chem. Soc. 1997, 119, 8921-8924.

(4) Weiner, S. J. J. Am. Chem. Soc. 1984, 106, 765-784.

(5) Weiner, S. J. J. Comput. Chem. 1986, 106, 230-252.

(6) Jorgensen, W. L.; Madura, J. D.; Swenson, C. J. J. Am. Chem. Soc. 1984, 106, 6638-6646.

(7) Briggs, J. M.; Nguyen, T. B.; Jorgensen, W. L. J. Phys. Chem. 1991, 95, 3315-3322.

(8) Jorgensen, W. L.; Briggs, J. M.; Contreras, M. L. J. Phys. Chem. 1990, 94, 1683-1686.

(9) Jaguar v3.5, Schrodinger Inc.: Portland, OR, 1998.

(10) Greeley, B. H.; Russo, T. V.; Mainz, D. T.; Friesner, R. A.; Langlois, J.-M.; Goddard III, W. A.; Donnelly, R. E.; Ringalda, M. N. J. Chem. Phys. 1994, 101, 4028-4041.

(11) Chirlian, L. E.; Francl, M. M. J. Comput. Chem. 1990, 8, 894-907.

(12) Woods, R. J.; Khalil, M.; Pell, W.; Moffat, S. H.; Smith Jr., V. H. J. Comput. Chem. 1990, 11, 297-310.

(13) Breneman, C. M.; Wiberg, K. B. J. Comput. Chem. 1990, 11, 361-373. 